\title{
Aortic decision-making in the Loeys-Dietz syndrome: Aortic root aneurysm and a normal-caliber ascending aorta and aortic arch
}

\author{
John G. T. Augoustides, MD, FASE, ${ }^{\mathrm{a}}$ Ted Plappert, CVT, ${ }^{\mathrm{b}}$ and Joseph E. Bavaria, MD ${ }^{\mathrm{c}}$
}

Loeys-Dietz syndrome (LDS) is a recently described autosomal dominant connective tissue disorder characterized by premature aggressive aortic aneurysm and dissection. ${ }^{1}$ Thoracic aortic dissection is the leading cause of death in this lethal vascular syndrome. ${ }^{2}$ We present a case of an aortic root aneurysm in a young man with LDS who underwent elective reconstruction of his aortic root, ascending aorta, and aortic arch. This aggressive surgical approach was both curative (aortic root aneurysm) and preventive (future high risk of type A dissection). This aggressive surgical management is presented to describe a preemptive approach to defend patients with LDS from devastating type A dissection. ${ }^{3}$

\section{CLINICAL SUMMARY}

A 15-year-old boy with LDS was referred for aortic reconstruction caused by an aortic root aneurysm. Serial assessment of the aneurysm diameter by means of computed axial tomographic analysis over the previous 2 years had documented a growth rate of more than $0.5 \mathrm{~cm} / \mathrm{y}$. The patient reported a recent repair of a deep pectus excavatum. On physical examination, he displayed characteristic physical stigmata of LDS, such as hypertelorism and joint hyperflexion. In addition to his sternotomy scar, the results of his precordial examination were normal. Preoperative transthoracic echocardiographic analysis revealed an aortic root aneurysm with a normally functioning trileaflet aortic valve and no other cardiovascular abnormalities.

In the operating room the patient underwent transesophageal echocardiography after achievement of general endotracheal anesthesia. The preoperative echocardiographic findings were confirmed. Furthermore, the aortic root dimensions were as follows: aortic annulus, $26 \mathrm{~mm}$; sinus of Valsalva maximal diameter, $38 \mathrm{~mm}$; sinotubular junction diameter, $29 \mathrm{~mm}$; and ascending aortic diameter, $25 \mathrm{~mm}$ (Figure 1). In anticipation of a possible valve-sparing aortic root replacement, meticulous echocardiographic examination of the aortic valve cups was performed. They were normal in structure, function, and motion pattern.

\footnotetext{
From the Cardiothoracic Section, Anesthesiology and Critical Care, ${ }^{a}$ University of Pennsylvania School of Medicine; the Quantitative Echocardiographic Laboratory, Division of Cardiology, Department of Medicine, ${ }^{\mathrm{b}}$ University of Pennsylvania Medical Center; and the Division of Cardiothoracic Surgery, Department of Surgery, ${ }^{\mathrm{c}}$ University of Pennsylvania School of Medicine, Philadelphia, Pa.

Received for publication May 14, 2008; revisions received June 4, 2008; accepted for publication June 15, 2008; available ahead of print July 28, 2008.

Address for reprints: John G. T. Augoustides, MD, FASE, Cardiothoracic Section, Anesthesiology and Critical Care, Dulles 680, HUP, 3400 Spruce St, Philadelphia, PA 19104-4283 (E-mail: yiandoc@hotmail.com).

J Thorac Cardiovasc Surg 2009;138:502-3

$0022-5223 / \$ 36.00$

Copyright (c) 2009 by The American Association for Thoracic Surgery doi:10.1016/j.jtcvs.2008.06.024
}

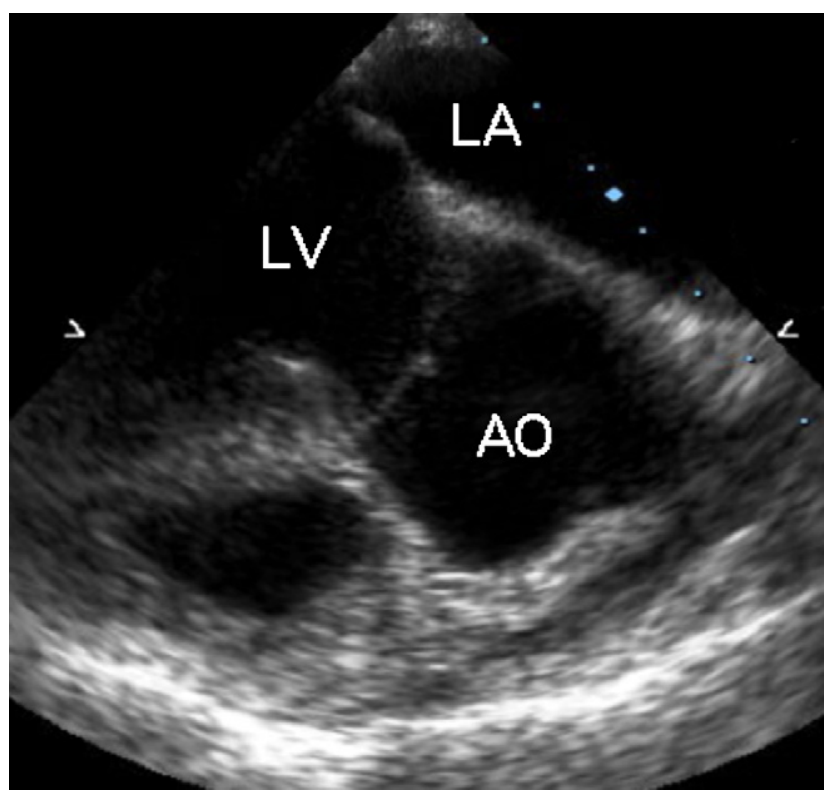

FIGURE 1. Transgastric long-axis view of the aortic root. There is an aortic root aneurysm with a maximal diameter of $38 \mathrm{~mm}$. There is no aortic dissection evident. $L A$, Left atrium; $L V$, left ventricle; $A O$, aortic root.

At surgical intervention during full cardiopulmonary bypass, prosthetic replacement of the aortic root and ascending aorta was performed. The coronary arteries were anastomosed with a button technique. The native aortic valve was reimplanted as per the David V technique (Figure 2). During deep hypothermic arrest and retrograde cerebral perfusion (total time, 20 minutes), an aggressive aortic hemiarch replacement was also performed. The cardiopulmonary bypass and myocardial ischemic times were 279 minutes and 244 minutes, respectively.

Separation from cardiopulmonary bypass was uneventful. Transesophageal echocardiographic analysis documented normal native aortic valvular function, a normal descending aorta, and normal biventricular function. There was minimal bleeding, and the patient required no blood component transfusion. The patient had a rapid postoperative recovery. After a brief stay in the intensive care unit, he was transferred to the surgical ward. His total hospital stay was 5 days.

\section{DISCUSSION}

This young man with LDS was referred for thoracic aortic intervention in a timely fashion. Regular thoracic aortic imaging resulted in an elective referral, namely rapid expansion of the aortic root aneurysm, a recognized indication for surgical intervention in patients with LDS. ${ }^{4}$ 


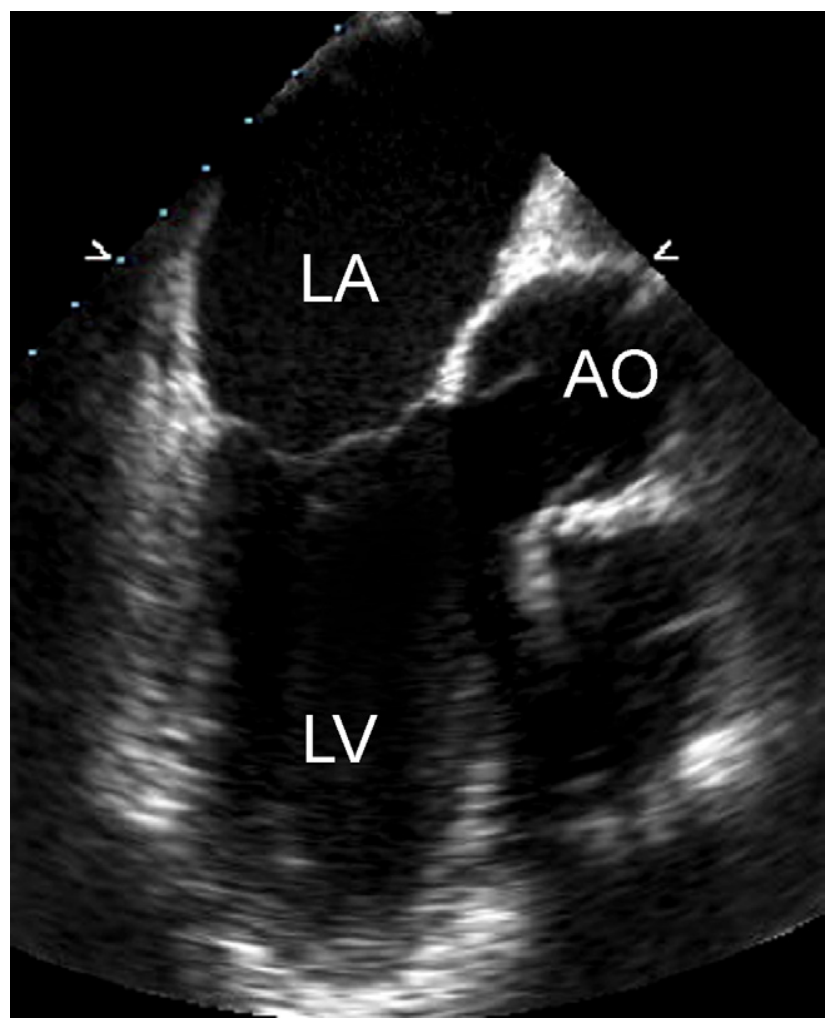

FIGURE 2. Midesophageal 2-chamber long-axis view of the aortic root. The prosthetic aortic root replacement is evident, with normal full systolic excursion of the reimplanted native aortic cusps (David V). $L A$, Left atrium; $L V$, left ventricle; $A O$, aortic root.

The minimum aortic procedure required was aortic root replacement. The sparing of the native aortic valve had the added advantages of excellent hemodynamics and no requirement for anticoagulation. Because the ascending aorta and aortic arch were of upper normal caliber, surgical replacement was not absolutely required at the same time.

Our rationale for concomitant replacement was 2-fold. First, it added negligible extra perioperative risk, given his young age and our extensive experience in aortic arch surgery. ${ }^{5} \mathrm{Sec}-$ ond, the patient was at a much higher risk of type A dissection in the near future, given the natural history of LDS. ${ }^{1-4}$

In summary, the clinical observation from this case is that surgical management of the proximal thoracic aorta in patients with LDS should take into account not only the presenting aortic pathology but also the likely future aortic syndromes based on the natural history of this aggressive vasculopathy. The aortopathy seen in patients with LDS merits an aggressive surgical approach, given its life-threatening presentations.

\section{References}

1. Loeys BL, Chen J, Neptune ER, Judge DP, Podowski M, Holm T, et al. A syndrome of altered cardiovascular, craniofacial, neurocognitive, and skeletal development caused by mutations in TGFBR1 or TGFBR2. Nat Gen. 2005;37:275-81.

2. Lee RS, Fazel S, Schwarze U, Fleischmann D, Berry GJ, Liang D, et al. Rapid aneurismal degeneration of a Stanford type B aortic dissection in a patient with Loeys-Dietz syndrome. J Thorac Cardiovasc Surg. 2007;134:242-3.

3. Melenovsky V, Adamira M, Kautznerova D, Voska L, Weichet J, Loeys B, et al. Aortic dissection in a young man with Loeys-Dietz syndrome. J Thorac Cardiovasc Surg. 2008; 135:1174-5.

4. Williams JA, Loeys BL, Nwakanma LU, Dietz HC, Spevak PJ, Patel ND, et al Early surgical experience with Loeys-Dietz: a new syndrome of aggressive thoracic aortic aneurysm disease. Ann Thorac Surg. 2007;83(suppl):S757-63.

5. Appoo JJ, Augoustides JG, Pochettino A, Savino JS, McGarvey ML, Cowie DC, et al. Perioperative outcome in adults undergoing elective deep hypothermic circulatory arrest with retrograde cerebral perfusion in proximal aortic arch repair: evaluation of protocol-based care. J Cardiothorac Vasc Anesth. 2006;20:3-7.

\title{
A simple modification of inflow cannula to reduce recirculation of venovenous extracorporeal membrane oxygenation
}

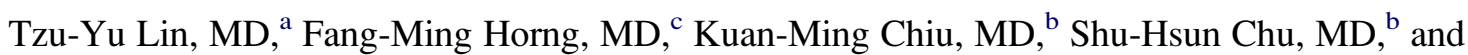 \\ Jiann-Shing Shieh, PhD, ${ }^{\mathrm{d}}$ Taipei and Tao-Yuan County, Taiwan
}

\footnotetext{
From the Department of Anesthesia, ${ }^{\mathrm{a}}$ Division of Cardiovascular Surgery, ${ }^{\mathrm{b}}$ and Division of Critical Care, ${ }^{\mathrm{c}}$ Far-Eastern Memorial Hospital, Taipei, Taiwan; and the Department of Mechanical Engineering, Yuan-Ze University, ${ }^{\mathrm{d}}$ Tao-Yuan County, Taiwan.

Received for publication Jan 28, 2008; accepted for publication Feb 27, 2008; available ahead of print Sept 1, 2008

Address for reprints: Fang-Ming Horng, MD, Division of Critical Care, Far-Eastern

Memorial Hospital, 13F, 21, Sec 2, Nan-Ya S Rd, Ban-Ciao, Taipei County, 220,

Taiwan (E-mail: philip@mail.femh.org.tw).

J Thorac Cardiovasc Surg 2009;138:503-6

$0022-5223 / \$ 36.00$

Copyright (C) 2009 by The American Association for Thoracic Surgery

doi:10.1016/j.jtcvs.2008.02.095
}

Venovenous extracorporeal membrane oxygenation (VVECMO) is commonly used in respiratory distress syndrome. Double cannulation of jugular and femoral veins is the most practical clinical setting for adult patients. Despite the excellent efficiency of membranous oxygenator, recirculation impairs oxygen delivery. There are several clinically practical methods to quantify and monitor recirculation in VV-ECMO applications. However, limited interventions could be done to reduce recirculation. Theoretically, an attempt to insert the inflow cannula into the 